\title{
Comparative assessment of seller's staining test (SST) and direct fluorescent antibody test for rapid and accurate laboratory diagnosis of rabies.
}

\author{
Ishaya S.Tekki, Zhakum N. Ponfa, Chika I. Nwosuh, Peterside R. Kumbish, Clement L. Jonah, \\ Philip A. Okewole, David Shamaki, Sani M. Ahmed
}

National Veterinary Research Institute (NVRI), PMB 01 Vom, Nigeria

\begin{abstract}
Background: Rabies causes 55, 000 annual human deaths globally and about 10,000 people are exposed annually in Nigeria. Diagnosis of animal rabies in most African countries has been by direct microscopic examination. In Nigeria, the Seller's stain test (SST) was employed until 2009. Before then, both SST and dFAT were used concurrently until the dFAT became the only standard method.

Objective: This study was designed to assess the sensitivity and specificity of the SST in relation to the 'gold standard' dFAT in diagnosis of rabies in Nigeria.

Methods: A total of 88 animal specimens submitted to the Rabies National Reference Laboratory, Nigeria were routinely tested for rabies by SST and dFAT.

Results: Overall, $65.9 \%$ of the specimens were positive for rabies by SST, while $81.8 \%$ were positive by dFAT. The sensitivity of SST in relation to the gold standard dFAT was $81.0 \%$ (95\% CIs; $69.7 \%-88.6 \%$ ), while the specificity was $100 \%$ (95\% CIs; $76 \%-100 \%)$.

Conclusion:The relatively low sensitivity of the SST observed in this study calls for its replacement with the dFAT for accurate diagnosis of rabies and timely decisions on administration of PEP to prevent untimely deaths of exposed humans. Keywords: Seller's Staining Test, direct fluorescent antibody test, rabies, diagnosis, Nigeria.

DOI: http://dx.doi.org/10.4314/ahs.v16i1.16

Cite as: Tekki IS, Ponfa ZN, Nwosuh CI, Kumbish PR, Jonah CL, Okewole PA, Shamaki D, Ahmed SM. Comparative assessment of seller's staining test (SST) and direct fluorescent antibody test for rapid and accurate laboratory diagnosis of rabies. Afri Health Sci. 2016;16(1): 123-127. bttp://dx.doi.org/10.4314/abs.v16i1.16
\end{abstract}

\section{Introduction}

Rabies is a fatal zoonotic disease of mammals caused by a highly neurotropic virus belonging to the Lyssavirus genus, in the family Rhabdoviridae ${ }^{1}$. The viral agent is transmitted to humans mainly through bites and scratches from infected animals ${ }^{2}$. Rabies is present on most continents, causing at least 55, 000 human deaths per year and is endemic in most African and Asian countries where most human deaths occur ${ }^{4}$.

Rabies is endemic in Nigeria with the domestic dog as the major vector of the causative agent ${ }^{5,6}$. Since its first occurrence in the country in humans in 1912 and first laboratory confirmed diagnosis in a dog in $1925^{7}$, hu-

\section{Corresponding author: \\ Ishaya S. Tekki, \\ National Veterinary Research Institute (NVRI), PMB 01 Vom, Nigeria \\ Tel: +2348036012637 \\ E-mail:ishaya.sinitekki@yahoo.com}

man and animal rabies cases have been recorded in all the regions and ecological zones of Nigeria annually, ${ }^{8}$. For instance, in 1942, rabies was reported from Kano Zaria Borno and Ilorin ${ }^{6,8,9}$ and from Plateau, Makurdi and Enugu in $1946^{10,11}$. Serological evidence of Lagos bat virus circulation among Nigerian fruit bats ${ }^{13}$, and rabies virus antigens in apparently healthy dogs in Yola, Nigeria $^{14}$ were also reported.

According to Nawathe ${ }^{15}$, no fewer than 10,000 Nigerians are exposed to rabies annually, and about 1,000 annual cattle mortality had been reported. In Nigeria, human and animal rabies cases are on the increase annually despite the availability of vaccines for its control and prevention ${ }^{12}$.

Although majority of the Veterinary Laboratories in Africa have adequate personnel capacity to diagnose rabies in animals, routine diagnosis is often constrained by lack of laboratory equipment and reliable reagents ${ }^{16,17}$. For instance, the direct microscopic examination by the SST, which due to its low sensitivity and reliability $^{18,19}$, had long been substituted with the more sen- 
sitive, specific and reliable direct fluorescent antibody test (dFAT) in most rabies laboratories globally, had not been employed in the diagnosis of rabies in Nigeria, until 2009. Although the dFAT was introduced in the laboratory since $2005^{20}$, its full implementation only began in September 2009 when the two year (2010 to 2011) "south-south twinning" agreement between the OIE reference laboratory for rabies, Onderstepoort Veterinary Institute, Pretoria, South Africa and NVRI, Vom, Nigeria, was signed. Before the full implementation of the dFAT however, there had been 8 months (March to October, 2009) of transition, during which both techniques were concurrently utilized in routine diagnosis of rabies. This study was therefore designed to compare the sensitivity and specificity of the SST with the 'gold standard' dFAT in routine diagnosis of rabies in animals in the rabies National Reference laboratory, Nigeria.

\section{Materials and methods \\ Data collection}

A total of 88 animal brain specimens were received for routine diagnosis of rabies in Central Diagnostic Laboratory, NVRI, Vom, Nigeria, from March to October 2009. Specimen submissions were from rabies-suspect animals and from animal carcases received for routine post mortem examination in the laboratory. Touch impression smears of the hippocampus on slides were fixed in chilled acetone and tested for the presence of rabies virus antigens by the dFAT as described by Dean et al. ${ }^{21}$; using rabies fluorescein isothiocyanate conjugated (FITC) Anti-Rabies Monoclonal Globulin (FDI FUJIREBIO Diagnostic, Inc.), according to manufacturer's instructions. Slides were examined under royal blue LED (455nm) excitation filter at X10 eye piece and X20 objective lenses using Fluorescence Microscope (Axioskop G/115-230).

Smears of the hippocampus were also made on another set of slides and stained with Sellers stain as described by Tierkel and Atanasiu ${ }^{19}$. The stained smears were examined under oil immersion (X100) magnification using a light microscope (Olympus $\mathrm{CH}$ ) for presence of eosinophilic stained rabies virus particles inclusions (Negribodies) in the cytoplasm the brain cells.

\section{Data analysis}

Data collected was compiled, processed and analysed. The sensitivity, specificity and predictive values of the SST were determined using the VassarStats (http:// www.vassarstats.net/clin1.html) and by Chi-square methods as described by Akobeng ${ }^{22}$.

\section{Results}

Comparative analysis of the two diagnostic techniques (Table 1; Figure 1) showed that, of the 88 specimens tested, $65.9 \%$ (58/88) and 81.8\% (72/88) were positive by SST and dFAT respectively, while $34.1 \%$ (30/88) and $18.2 \%(16 / 88)$ were negative by the respective tests. Fourteen (14) of the 30 samples that tested negative by SST were positive by the gold standard dFAT (Table 1).

\section{Table 1: Overall result of rabies diagnosis by SST and dFAT in NVRI, Vom, Nigeria from March to October, 2009.}

\begin{tabular}{llll}
\hline Technique/ Result & dFAT +ve & dFAT - ve & Total
\end{tabular}

\begin{tabular}{cccc}
\hline Sellers +ve & 58 & 0 & $\mathbf{5 8}$ \\
Sellers -ve & 14 & 16 & $\mathbf{3 0}$ \\
Total & $\mathbf{7 2}$ & $\mathbf{1 6}$ & $\mathbf{8 8}$ \\
& & & \\
\hline
\end{tabular}


The sensitivity of SST in relation to the 'gold standard' dFAT was $81.0 \%(95 \%$ CIs; $69.7 \%-88.6 \%)$ while the specificity was $100 \%$ (95\% CIs; $76 \%-100 \%)$. The true prevalence and the approximate Prevalence of rabies by SST were $81.8 \%$ and $65.9 \%$ respectively. The positive predictive value (PPV) of the SST was $100 \%$, while the negative predictive value (NPV) was $53.3 \%$.

\section{Discussion}

In 72 of the 88 specimens tested by dFAT, $81.8 \%$ where positive for rabies while oval or round magenta red coloured Negri bodies were seen in only $58(65.9 \%)$ of specimens stained with seller's stain. This indicated that majority of the animals were infected with rabies virus. However, the results showed that only 58/72 (80.5\%) of the rabies positive specimens by dFAT showed presence of Negribodies in SST (Table 1, Figure 1). The lower positivity of the SST $(65.9 \%)$ compared to the dFAT $(81.8 \%)$ (Figure 1) and the ability of the dFAT to detect rabies antigen in 14 of the 30 specimens that tested negative by the SST (Table 1) is in harmony with the lower sensitivity and reliability of the SST technique ${ }^{23}$ compared to the 'gold standard' test. Negri bodies seen in $65.9 \%$ of the specimens by SST in this study were comparable with the 50-60\% reported earlier ${ }^{24}$.

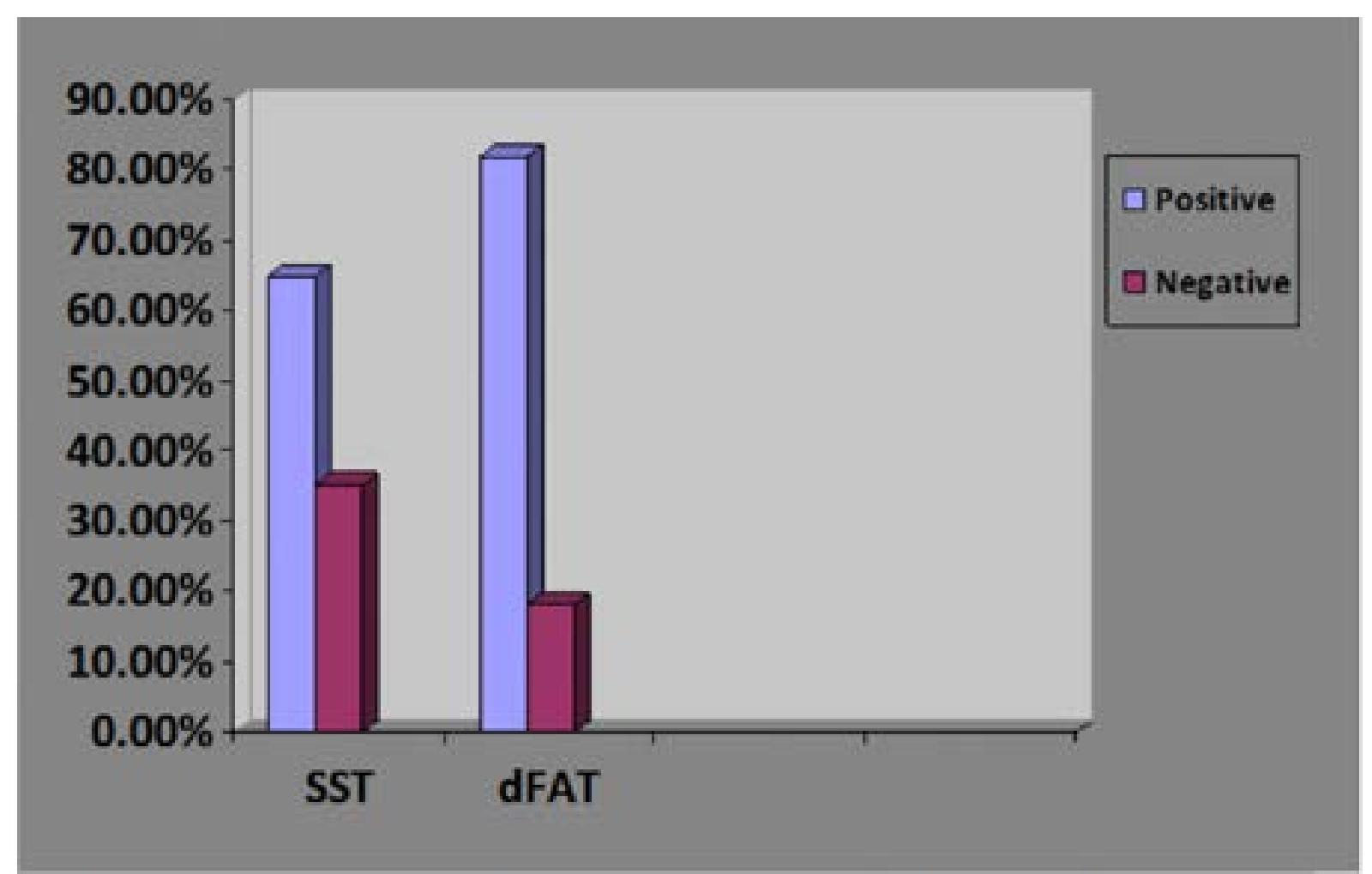

\section{Comparative analysis of SST and dFAT in the diagnosis of rabies in NVRI, Vom, Nigeria from March to October, 2009}

\section{SST - Seller's staining test \\ dFAT - direct fluorescent antibody test \\ NVRI - National Veterinary Research Institute}

The sensitivity of SST in relation to the "gold standard" dFAT was $81.0 \%$ (95\% CIs; 69.7\% - 88.6\%), while the specificity was $100 \%(95 \%$ CIs; $76 \%-100 \%)$. This showed that SST missed rabies virus antigen in some positive samples in the study resulting in false negative results. However, the high specificity of the SST means there were no false positive results from samples that tested positive by the SST. Therefore, a positive result guarantees that the sample is truly positive while negative result does not. This further implies that, the Sell- er's method is only most useful to the clinician when the test result of rabies suspect animal is positive, but doubtful when result is negative.

Given that rabies is a deadly disease with $100 \%$ case fatality rate once the virus has entered the central nervous system (CNS), a highly sensitive, rapid, reliable and standardized technique is desirable for its accurate diagnosis. The dFAT has been reported to be $98-100 \%$ sensitive ${ }^{23}$ and $99.6 \%$ specific while the SST has $90.5 \%$ 
sensitive and $98.8 \%$ specific $^{25}$. This showed that although Negri bodies are specific for rabies virus infection, SST is less sensitive and specific as it only detects affinity of Negri bodies for acidophilic stains ${ }^{26}$. It has also been shown that Negri bodies are not developed in all infected individual ${ }^{26}$ and cannot be demonstrated by the SST in all animals from which the virus can be isolated ${ }^{27}$. Consequently, false negative results may occur in some infected materials and false positive results may occur if nonspecific inclusion bodies are present in tissue samples tested ${ }^{26}$. On the contrary, the dFAT has a high degree of sensitivity and specificity ${ }^{28}$ and provides a reliable diagnosis in $98-100 \%$ cases $^{21}$. With sufficient care and experience, fluorescent antibody techniques can be used with considerable speed and accuracy for the determination of the presence of rabies virus in the salivary glands of animals ${ }^{27}$.

Therefore, it is recommended to routinely use dFAT for rapid and accurate diagnosis of rabies in rabies-suspect animals in order to take right and timely decision on administration of PEP to exposed humans. An accurate laboratory diagnostic result obtained by dFAT within few hours [1-2 hours] could save the victim from avoidable death if the animal is rabid and the full course of PEP is administered to the victim within the recommended time. An accurate result would also save persons exposed to rabies from trauma and financial burden associated if the animal is not rabid ${ }^{23}$.

\section{Conclusion}

Although the SST has the advantages of yielding results under one hour, inexpensive laboratory equipment needed to perform the test and the need to keep specimens cold after fixation is avoided, it can no longer be recommended for rabies routine diagnosis because it has comparatively low sensitivity and should be replaced with the dFAT ${ }^{24}$, wherever it is still being employed in rabies routine diagnosis.

\section{Acknowledgement}

We sincerely thank Dr Cluade Sabeta, ARC-OVI, Pretoria for thoroughly reviewing the manuscript and Dr Pius Ekong, Epidemiology Unit, NVRI, Vom, Nigeria, (Currently, a Graduate Research Assistant -- Kansas State University) for the VassarStats Printable Report of computed values and providing the Clinical Calculator 1 link.

\section{References}

1. Pringle CR. The Order Mononegavirales. Archives of virology 1991; 117: 137-40.

2. WHO. Rabies. Animal bites Fact Sheet $N^{\circ} 99$ http:// www.who.int/mediacentre/factsheets/fs099/en/ (2015). Accessed, 9 September, 2015.

3. WHO Expert Consultation on Rabies. First Report. World Health Organ Tech Rep Ser. 2005; 931: 1-88. Available from: http://www.who.int/rabies/Expert Consultation On Rabies.pdf Accessed, 1 May, 2015.

4. Knobel DL, Cleaveland S, Coleman PG, Fevre EM, Meltzer MI, Miranda ME et al. Re-evaluating the burden of rabies in Africa and Asia. Bull World Health Organ 2005; 83: 360-8.

5. Tomori O. Wild life rabies in Nigeria: experimental infection and transmission studies with the shrew (Crocidura sp.). Annals of Tropical Medicine and Parasitology 1980; 74(2):151-6.

6. Ogunkoya AB. Rabies: Basic Concepts, Problems and Prospects of its Control in Nigeria. Oreofe Nig. Limited Publishers: Akure, Nigeria 1997.

7. Boulger LR and Porterfield JS. Isolation of a Virus from Nigerian Fruit Bats. Transactions of Royal Society of Tropical Medicine and Hygiene1958; 52: 421-424.

8. Owolodun BY. Rabies Present Situation in Nigeria. West African Medical Journal 1969; Published online 2010 doi: 10.1128/JCM.01256-10. Accessed, 18 April, 2015

9. Familusi JB and Moore DL. Isolation of Rabies Related Viruses from the Cerebrospinal Fluid of a Child with Aseptic Meningitis. African Journal of Medical Science 1972; 3: 93-6.

10. Okoh AE. Canine rabies in Nigeria, 1970 - 1980 reported cases in vaccinated dogs. International Journal of Zoonoses 1982; 9 (2):118-25.

11. Ogboegbulem SA. Rabies in Man and Animals. Fidelity Publishers: 12 Unije Street Independence Layout Enugu; 199.

12. Ogunkoya AB. Review of Rabies and Problems of Rabies in Nigeria. Proceedings of the National Conference/workshop on Rabies: IDR- ABU, Zaria, Nigeria; 2008; p. 62-70.

13. Dzikwi AA, Kuzmin II, Umoh JU, Kwaga JKP, Ahmad AA and Rupprecht CE. Evidence of Lagos Bat Virus Circulation among Nigerian Fruit Bats. Journal of Wildlife Diseases 2010; 46 (1): 267-71.

14. Aliyu TB, De N, Yenda EN and Lynn M. Prevalence of Rabies Virus Antigens in Apparently Healthy Dogs in Yola, Nigeria. Researcher 2010; 2:2. 
15. Nawathe DR. Rabies inNigeria. Bulletin of Office International des Epizooties 1980; 92: 129-39.

16. Mallewa M, Fooks AR., Banda D, Chikungwa P, Mankhambo L, Molyneux E et al. Rabies encephalitis in malaria-endemic area, Malawi, Africa. Emerging infectious diseases 2007; 13:1

17. Weyer J. Human rabies in South Africa: An overview of epidemiological and diagnostic features. In: Proceedings of 9th South East African Rabies Group (SEARG) meeting, Gaborone, Botswana, 25-28/08/2008.

18. Barrat J. Experimental diagnosis of rabies: Adaptations to field and tropical conditions. In: Proceedings of the International Conference on Epidemiology, Control and Prevention of Rabies in Eastern and Southern Africa. Lusaka, Zambia, 2-5 June 1992; 72-83.

19. Tierkel ES, Atanasiu P.Rapid microscopic examination for Negri bodies and preparation of specimens for biological tests. In: Meslin F-X, Kaplan MM, Koprowski $\mathrm{H}$, editors. Laboratory techniques in rabies. 4. Geneva: World Health Organization; 1996. p. 55-65. 20. Tekki IS, Okewole PA, Ekong SP, Kumbish PR, Shamaki D and Ahmed MS. Control of Rabies and Rabies Related Viruses in Nigeria: Perspectives from the National Veterinary Research Institute, Vom, Nigeria. Epizootiology and Animal Health in West Africa 9: RIWA Journal 2013; 1:102 - PubMed ; 5.

21. Dean DJ, Ableseth MK and Atanasiu P. The fluorescent antibody test. In: Meslin F-X, Kaplan MM, Koprowsky H, editors. Laboratory Techniques in Rabies. 4th edition. Geneva, Switzerland: WHO; 1996. p. 88-96.
22. Akobeng AK. Understanding diagnostic tests 1: Sensitivity, specificity and predictive values. ACTA Paediatrica 2006; 96: 338-41 PubMed .

23. CDC. Rabies Diagnosis. National Centre for Emerging and Zoonotic Infectious Diseases (NCEZID), Division of High-Consequence Pathogens and Pathology (DHCPP) http://www.cdc.gov/rabies/diagnosis/index.html (2011) Accessed, 25 March, 2015.

24. OIE. Manual of Diagnostic Tests and Vaccines for Terrestrial Animals; Chapter2.1.13. http://www. oie.int/fileadmin/Home/eng/Health_standards/ tahm/2.01.13_RABIES.pdf (2013). Accessed, 25 March, 2015

25. Robles CG and Miranda NLJ. Comparative evaluation of the rabies fluorescent antibody test and direct microscopic examination at the research institute of tropical medicine. Phil J Microbiol Infect Dis 1992; 21(2): 69-72

26. Sellers TF. A new method for staining negribodies of rabies. Amer. J. Publ. Hlth. 1927; 17:1080. IJAVMS, Vol. 6, Issue 4, 2012: 229-240 doi: 10.5455/ijavms. 11894. PubMed

27. Goldwasser RA, Kissling RE, Carski TR. Fluorescent Antibody staining of rabies virus antigens in the salivary glands of rabid animals. Bull. Wld Hith Org., 1959; 20: 579-588

28. Whitfield SG, Fekadu M, Shaddock JH. A comparative study of the fluorescent antibody test for rabies diagnosis in fresh and formalin-fixed brain tissue specimens. J. Virol. Methods.2001; 95:145-151. 